\title{
Research on "Static-Dynamic" Development of Characteristic Towns in China Based on Space and Type: A Big Data Analysis
}

\author{
Shuoyang Cao, Tianzhu Li, Haotian Gao \\ School of Business Administration, University of Science and Technology Liaoning, Anshan, China \\ Email: csy9633@163.com
}

How to cite this paper: Cao, S.Y., Li, T.Z. and Gao, H.T. (2019) Research on "Static-Dynamic" Development of Characteristic Towns in China Based on Space and Type: A Big Data Analysis. American Journal of Industrial and Business Management, 9, 1639-1652.

https://doi.org/10.4236/ajibm.2019.98107

Received: July 18, 2019

Accepted: August 10, 2019

Published: August 13, 2019

Copyright $\odot 2019$ by author(s) and Scientific Research Publishing Inc. This work is licensed under the Creative Commons Attribution International License (CC BY 4.0).

http://creativecommons.org/licenses/by/4.0/

(c) (i) Open Access

\begin{abstract}
Using the idea of big data analysis, this paper makes a quantitative analysis of the development of characteristic towns in China based on two dimensions of space and type, static and dynamic, and puts forward policy suggestions. The results showed that: distribution density of characteristic towns in China is dense and stratified, which decreases from east to west. There are significant differences in distribution density between different types of towns. The development of small towns follows the evolution trajectory of "enlightenment-initial development-high speed development-normative construction" and forms a ladder transfer pattern of "Zhejiang-southeast coast-national-southeast coast". Town construction is highly resource embeddedness, and is undergoing a transition from resource-driven to innovation-driven.
\end{abstract}

\section{Keywords}

Characteristic Town, Static Distribution, Dynamic Evolution, Big Data Analysis

\section{Introduction}

In recent years, as an important grasp of China's new urbanization strategy, characteristic towns with the integration of "production, city, people and culture" have attracted much attention. Characteristic towns originated at the end of the 19th century, at that time, many industrial towns and resource-based towns in developed countries from Europe and America turned to characteristic development because of environmental pollution or resource exhaustion [1]. At the end of 1970s, a number of specialized towns appeared in the world, such as Silicon Valley (Science and Technology Town), Greenwich (Fund Town), Pro- 
vence (Leisure Tourism Town) and so on. In 2014, Zhejiang Province first put forward the concept of characteristic towns in China, and created this innovative space as a new carrier of industrial transformation and upgrading. In the 13th Five-Year Plan, it is proposed to develop small towns with distinctive characteristics, industry-city integration and full of charming according to local conditions [2]. In July 2016, a number of national departments jointly issued the "Notice on the Cultivation of Characteristic Towns" which marked the starting of the construction of characteristic towns in China. In 2017, the "characteristic small towns" were included in the government work report for the first time. At the Central Economic Work Conference held at the end of 2018, General Secretary Xi Jinping put forward the specific requirements of "guiding the healthy development of characteristic towns", which further highlighted the strategic position of characteristic towns.

At present, China's characteristic towns are developing rapidly. Therefore, clarifying the distribution characteristics and evolution rules of characteristic towns in China has practical significance for guiding the healthy development of characteristic towns, policy making and so on. Some scholars have discussed the development of characteristic towns in China, such as the analysis of the development mode and mechanism of small towns [3] [4], and put forward the governance path in view of the existing problems in the construction of characteristics towns [5], etc. But according to the existing research, there are still two weaknesses: one is that the number of samples used in the study is too small to truly reflect the laws and characteristics of the development of small towns with Chinese characteristics; the other is that the study of characteristic towns mainly focuses on static and single-dimensional analysis, which makes it difficult to fully describe the development status and track of characteristic towns in China. Therefore, this paper collects a large number of data of characteristic towns in China to make up for the small number of samples in previous studies. Although the data of all characteristic towns cannot be collected, the amount of data in this paper is enough to show the real situation of the development of characteristic towns in China, so the empirical research is of practical significance.

In general, the article consists of four parts. First, the analysis method, selection of indicators and data collection are introduced. Secondly, the spatial distribution, type distribution and "space-type" distribution of characteristic towns are analyzed under static conditions. Thirdly, combined with the time dimension, the overall evolution of the national characteristic towns, "quantity-space" evolution and "type-space" evolution are analyzed from a dynamic perspective. Finally, summarize the development status of characteristic towns in China and give countermeasures and suggestions. By adopting big data analysis method, econometric analysis is conducted on the distribution rules of characteristic towns in China from two aspects of static and dynamic based on two dimensions of space and type. The paper further visualizes the evolution path of characteristic towns in China, and provides references for the construction and operation subjects of characteristic towns and the competent government departments. 


\section{Research Design}

\subsection{Analytical Methods}

Big data has become a major means and information asset for people to understand the world. The essence of big data analysis is a modern statistical method, which collects, records, analyses and predicts super-large-scale clustering phenomena by using advanced network technologies such as cloud computing and computing device [6]. Schonberger believes that the core of big data analysis is "full data model" and "sample $\approx$ totality" [7]. That is to say, previous small sample sampling analysis is not enough to truly reflect the law of things' development, while large data analysis can better explain the problem and discover the law. In view of the existing research's shortcomings, this paper uses the idea of large data analysis to carry out full-sample econometric analysis, hoping to give full play to the advantages of large data analysis and depict the distribution and evolution of characteristic towns more authentically and objectively.

\subsection{Analysis Index}

In order to reveal the spatial and type distribution and evolution of characteristic towns in China from both static and dynamic dimensions, this paper uses the coefficient of variation, nuclear density estimation and other indices, and carries out large-scale data analysis with ArcGIS, Excel and other software. The analysis function of Excel can clearly show the changing trend of the type and quantity of characteristic towns, ArcGIS can visualize the spatial distribution, the coefficient of variation can reflect the spatial distribution types, and the nuclear density estimation is an important index to judge the distribution characteristics of characteristic towns. The specific calculation formulas and meanings are shown in Table 1.

\subsection{Data Collection and Denoise}

According to the requirement of big data analysis, the following data are collected and sorted out in this paper. 1) Data of 1583 characteristic towns in 31

Table 1. Analytical indices and their implications.

\begin{tabular}{|c|c|c|}
\hline Index & Formula & Explanation and significance of formula \\
\hline $\begin{array}{l}\text { Coefficient of } \\
\text { variation }\end{array}$ & $\mathrm{CV}=100 \% \times \frac{\sqrt{\frac{\sum_{i=1}^{n}\left(S_{i}-\bar{S}\right)^{2}}{n}}}{\bar{S}}$ & $\begin{array}{l}\text { CV represents the coefficient of variation of Tyson polygon area in characteristic town; } S_{i} \\
\text { denotes the area of the } i \text { th Tyson polygon; } \mathrm{n} \text { is the number of Tyson polygon; } \\
\sqrt{\frac{\sum_{i=1}^{n}\left(S_{i}-\bar{S}\right)^{2}}{n}} \text { is standard deviation; } \bar{S} \text { is average value; } 33 \%<\mathrm{CV}<64 \% \text { is random } \\
\text { distribution; } \mathrm{CV} \geq 64 \% \text { is clustered distribution; } \mathrm{CV} \leq 33 \% \text { is uniform distribution }\end{array}$ \\
\hline $\begin{array}{c}\text { Nuclear density } \\
\text { estimation }\end{array}$ & $f(x)=\frac{1}{T h} \sum_{i=1}^{T} k\left(\frac{x-X_{i}}{h}\right)$ & $\begin{array}{l}f(x) \text { is the nuclear density estimates; } k\left(\frac{x-X_{i}}{h}\right) \text { is a kernel function; Tdenotes the } \\
\text { number of characteristic towns; } h>0 \text { is bandwidth; }\left(x-X_{i}\right) \text { is the distance from the } \\
\text { valuation point } x \text { to the event point } X_{i} \text {. The larger the nuclear density estimation, the more } \\
\text { dense the points, the higher the probability of regional events. }\end{array}$ \\
\hline
\end{tabular}


provinces, autonomous regions and municipalities directly under the Central Government (excluding Hong Kong, Macao and Taiwan) (Figure 1). 2) Longitudinal and latitude data of characteristic towns. 3) Setup time data. 4) Data of industry types of characteristic towns. The list of characteristic towns sorted out above is composed of characteristic towns approved twice by the state, provinces, and characteristic towns on Sina, Sohu, Tencent and other websites. Longitudinal and latitudinal data comes from Baidu Map Picking Coordinate System, and time and industry type data comes from Baidu Web page. Data collection is up to December 31, 2018. In order to ensure the comprehensiveness, authenticity and timeliness of the data, 1583 characteristic towns have been excluded those that have been eliminated and repeated.

\section{Static Analysis Results}

\subsection{Spatial Distribution of Characteristic Towns}

Longitudinal and latitudinal coordinates of characteristic towns are obtained by using Baidu Map Picking-up Coordinate System and imported into ArcGIS. The coordinates are presented on the map of China as dots. Then the variation coefficient is used to analyze the relative change degree of the point targets in space, so as to determine the spatial distribution characteristics of characteristic towns in China. Therefore, on the ArcGIS platform, with 1584 sample points as the center of mass, the Tyson polygon Voronoi map is created by using the tool module (Figure 2). Using formula (1), the results show that the average area of 1584 polygons is $0.6076 \mathrm{~km}^{2}$, the standard deviation is 2.1297 and the $\mathrm{CV}$ value is $350.51 \%$. Judging from this, China's characteristic towns are densely distributed in space. Based on the analysis of inter-provincial spatial distribution, the average distribution density of characteristic towns in China is 1.65 per 10,000 $\mathrm{km}^{2}$. Among them, Hainan Province has the highest density, reaching 29.71 per $10,000 \mathrm{~km}^{2}$; Tianjin has the second highest density, 26.55 per $10,000 \mathrm{~km}^{2}$; density in Zhejiang, Shanghai, Shandong and Jiangsu have decreased in turn, which is 20.20 per $10,000 \mathrm{~km}^{2}, 14.29$ per $10,000 \mathrm{~km}^{2}, 8.26$ per $10,000 \mathrm{~km}^{2}$ and 7.60 per $10,000 \mathrm{~km}^{2}$; Inner Mongolia, Xinjiang and Qinghai have the lowest density, which is less than 0.1 per $10,000 \mathrm{~km}^{2}$.

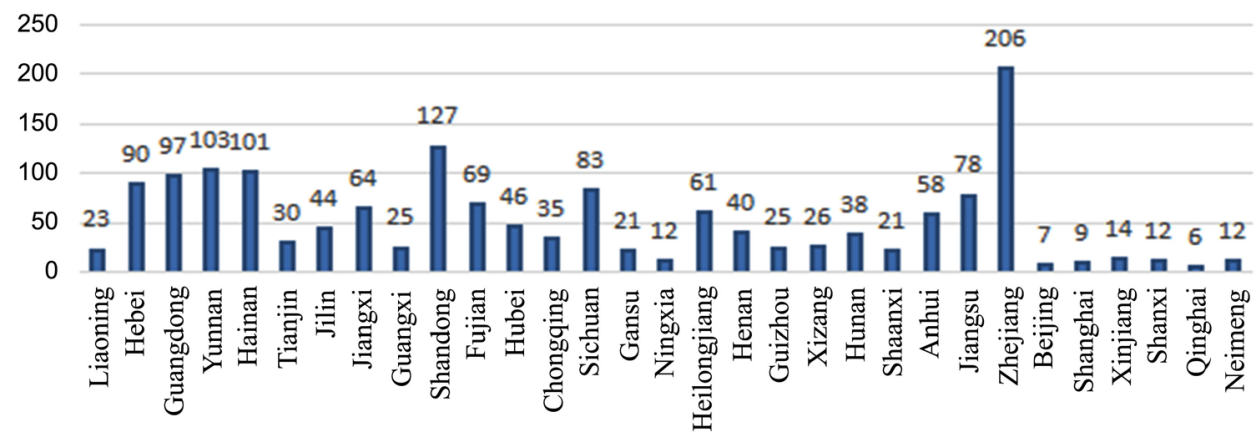

Figure 1. Quantity distribution of characteristics towns. 


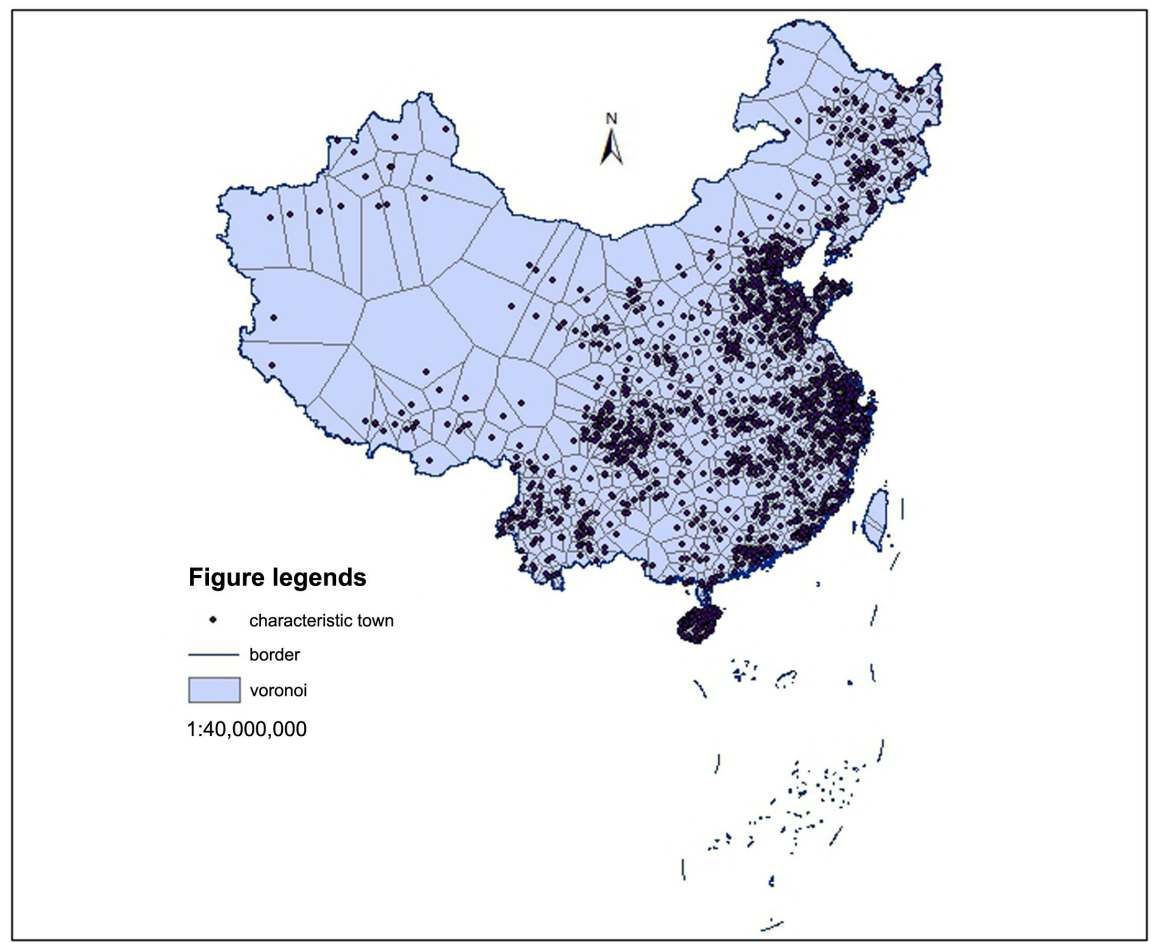

Figure 2. Tyson polygon of characteristic towns.

In order to further determine the spatial agglomeration heat zone of characteristic towns in China, we use the density analysis tool module of ArcGIS to generate the nuclear density map of characteristic towns (Figure 3). It is found that the characteristic towns in China have obvious agglomeration and hierarchy. On the whole, the density of characteristic towns shows a decreasing trend from east to west. Among them, 1) the dense areas are mainly located in Beijing-Tianjin, Yangtze River Delta and Hainan, with Zhejiang as the representative of the Yangtze River Delta as the highest density heat zone in China; 2) the denser areas are mainly distributed in the central part of Jilin, southeastern Hebei, northeastern Shandong, northern Henan, southern Anhui, eastern Hunan, western Jiangxi, central Hubei, Sichuan and Chongqing, eastern Guangdong, southern Fujian, eastern and western Yunnan, especially in the Pearl River Delta; 3) the characteristic towns in Liaoning, Heilongjiang, Shanxi, Shaanxi, Gansu, Qinghai, Xinjiang and Tibet distribute sporadically.

\subsection{Type Distribution of Characteristic Towns}

The core of characteristic towns is industrial development, with emphasis on "characteristic elements" [8]. According to the relevant classification research [3] [9], combined with the requirements of the State Council's "Some Opinions on Further Promoting the Construction of New Urbanization" and the National Development and Reform Commission and the Ministry of Finance's "Notice on Developing the Cultivation of Characteristic Towns" for the industrial positioning of characteristic towns. We divide characteristic towns into nine industrial 


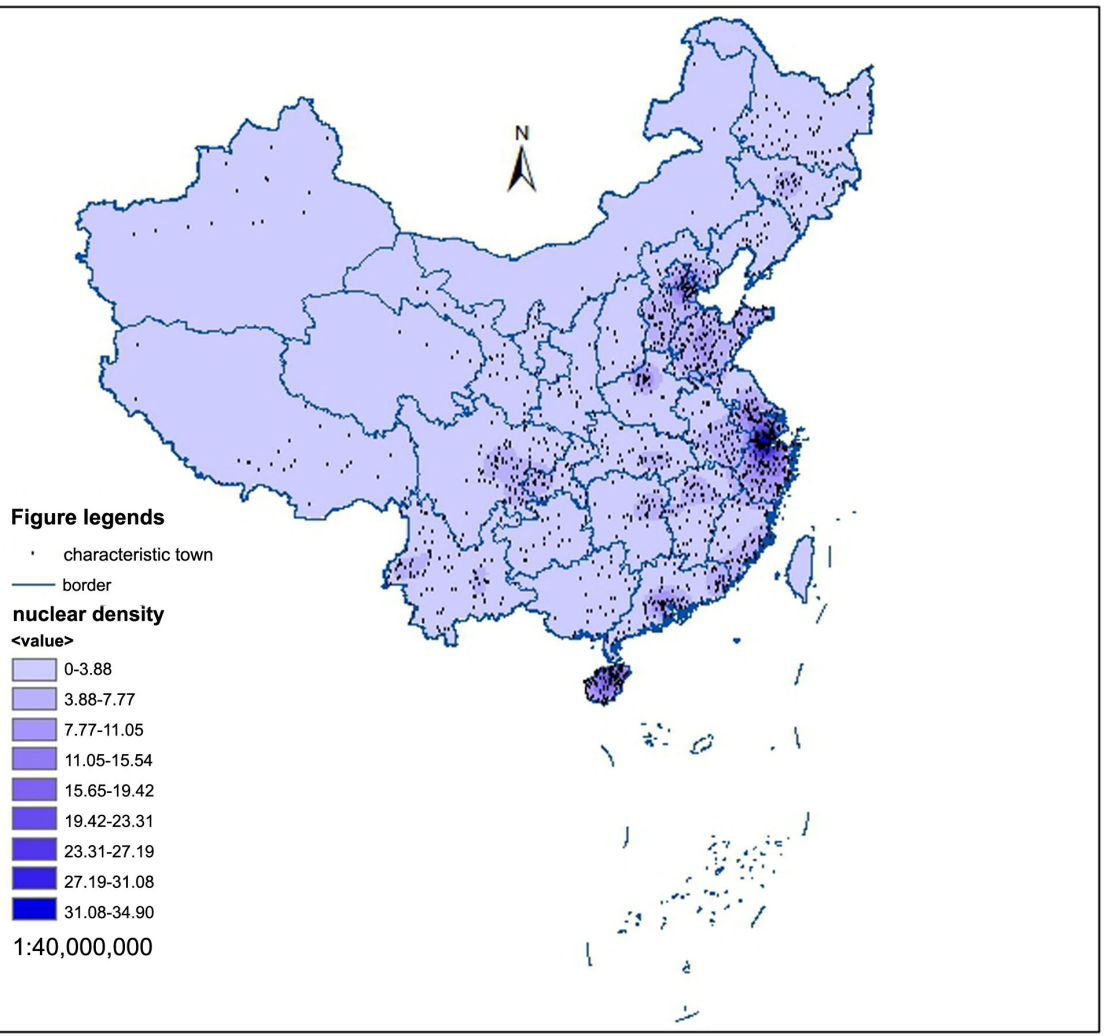

Figure 3. Nuclear density of distribution of characteristic towns in China.

types: tourism, manufacturing, modern agriculture, culture, information technology, business logistics, medical health, innovative ideas and finance. In the follow-up, we simplify the names of "tourist towns" and "manufacturing towns" respectively. Among the industrial types of characteristic towns, some towns may contain many kinds of industrial types. Therefore, the leading industries of characteristic towns are classified and the samples are not repeated. The results show that: 1) tourism towns account for the largest proportion, accounting for $38.83 \%$ of the total number of characteristic towns in China. From the perspective of grounded natural resources endowment, natural landscape and natural resources are the most easily explored part of the regional characteristics, which can explain why tourism characteristic towns develop most rapidly; 2) manufacturing towns account for $17.17 \%$ of the total number of national characteristic towns, which is probably due to the development of manufacturing industry clusters in China; 3) modern agricultural towns account for $14.77 \%$ of the total number of towns with national characteristics, which indicates that the original agricultural foundation provides an opportunity for the construction of modern agricultural towns; 4) cultural towns, information technology towns, business and logistics towns and medical and health towns account for $7.26 \%, 6.63 \%$, $6.19 \%$ and $6.00 \%$ of the total, and there was still much room for development; 5) innovative and creative towns and financial towns developed relatively slowly, accounting for $1.89 \%$ and $1.26 \%$ of the total number of towns with national cha- 
racteristics.

\subsection{Distribution of "Type-Space" in Characteristic Towns}

In order to explore the spatial distribution of different types of characteristic towns, the nuclear density maps of different types of characteristic towns are generated by means of density analysis tools of ArcGIS (because of many types of towns, this paper does not present nuclear density maps separately, but only in words). The results show that there are significant differences in spatial distribution density of different types of characteristic towns. 1) Tourism towns are abundant in quantity but scattered in distribution, mainly concentrated in the southeastern region of China, which is rich in natural resources, convenient transportation, beautiful scenery and suitable for leisure and vacation. Hainan is the core area of density. 2) Manufacturing towns are mainly distributed in the eastern and southern coastal areas of China, Beijing, Jiangsu, Zhejiang, Guangdong and other places because of its developed manufacturing industry and communication. 3) Modern agricultural towns are distributed evenly, mainly in Northeast China, North China, the middle and lower reaches of the Yangtze River and Sichuan. These areas have become high-density areas for developing agriculture and planting industry with their advantages of climate, soil and water resources. 4) Cultural towns are mainly distributed in China's regional cultural areas, such as Wuyue, Qilu, Yanzhao, Bashu, Lingnan and Southwest Minority Cultural Areas. 5) The distribution of information technology towns and commercial and logistics towns is more consistent, mainly concentrated in "Beijing-Tianjin", "Jiangsu-Zhejiang" and "Zhuhai-Shenzhen" areas, which is with local talent. 6) The distribution of medical and health towns is scattered, mostly in the eastern and southern regions of China with pleasant climate, less pollution, good medical conditions and convenient transportation. 7) Innovative and creative towns and financial towns are concentrated in Zhejiang, probably because Zhejiang first proposed the creation of dream towns and fund towns, which have rich experience in the development of these two types of towns.

\section{Dynamic Evolution Analysis}

In order to reveal the law of the development of characteristic towns, time variable is introduced to analyze the dynamic evolution of small towns on the basis of static analysis. This paper gives priority to the establishment time of characteristic towns according to the publication time of national and provincial approval documents. For some characteristic towns from the portal website, it searches the relevant news one by one in the webpage, and takes the earliest news reporting time as the establishment time of the town. Through the collation of time data, it is found that the establishment time of Characteristic Towns in China is 2012-2018, but the number of small towns in 2012 and 2013 is not statistically regular (there is only one in that year), and the term "characteristic towns" was formally put forward in 2014. Therefore, ignoring the data before 2014, the 
analysis draws a histogram of the town creation time (Figure 4).

\subsection{Overall Evolution of the Construction of Characteristic Towns in China}

As can be seen from Figure 4, the initial development of Characteristic Towns in China was relatively slow, only one in January 2014, but soon entered the high-speed development channel. In October 2015, the number of characteristic towns was 94. In October 2016, the construction of characteristic towns reached its first peak, reaching 131. June 2017 is the second peak of the creation of characteristic towns, the number of which has reached 197 nationwide. August 2017 is the historical peak of the construction of characteristic towns. The number of characteristic towns created in the whole country reached 387 in that month. Since then, the establishment of small towns with national characteristics has begun to stabilize. Although the number of towns created in October 2018 reached 104, they have generally entered the downstream channel. Further analysis is made according to the year of the establishment of characteristic towns (Figure 5). It is found that the construction of characteristic towns in China can be divided into four main stages. 1) Enlightenment (2015). In June 2015, Zhejiang announced the list of the first batch of characteristic towns, marking the beginning of the construction of characteristic towns in China. 2) The initial stage of development (2016). The announcement of the national policy document on the construction of characteristic towns in 2016 formally set off the upsurge of the construction of characteristic towns. Provinces began to formulate relevant cultivation policies, and characteristic towns blossomed all over the country. 3) The stage of high-speed development (2017). At this stage, the state announced the establishment list of the second batch of characteristic towns, which accelerated the development of the national characteristic towns. 4) Standardize the construction stage (2018). At this stage, a series of problems such as "real estate" and "uniformity" appeared in the construction and development of characteristic towns were put forward. The state issued "Several Opinions on Standardizing and Promoting the Construction of Characteristic Towns and Characteristic Towns", which led the construction of characteristic towns to the track of healthy development.

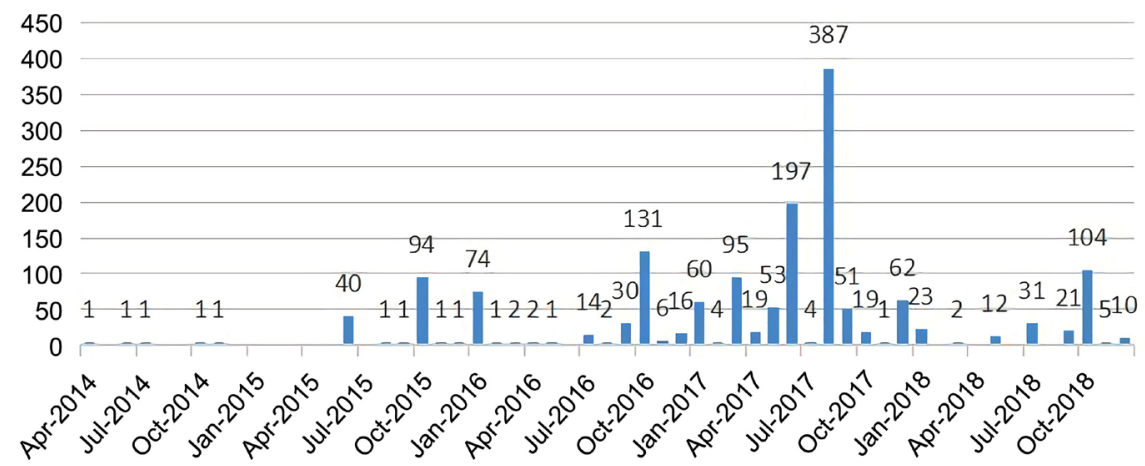

Figure 4. Time histogram of the establishment of characteristic towns in China. 


\section{quantity}

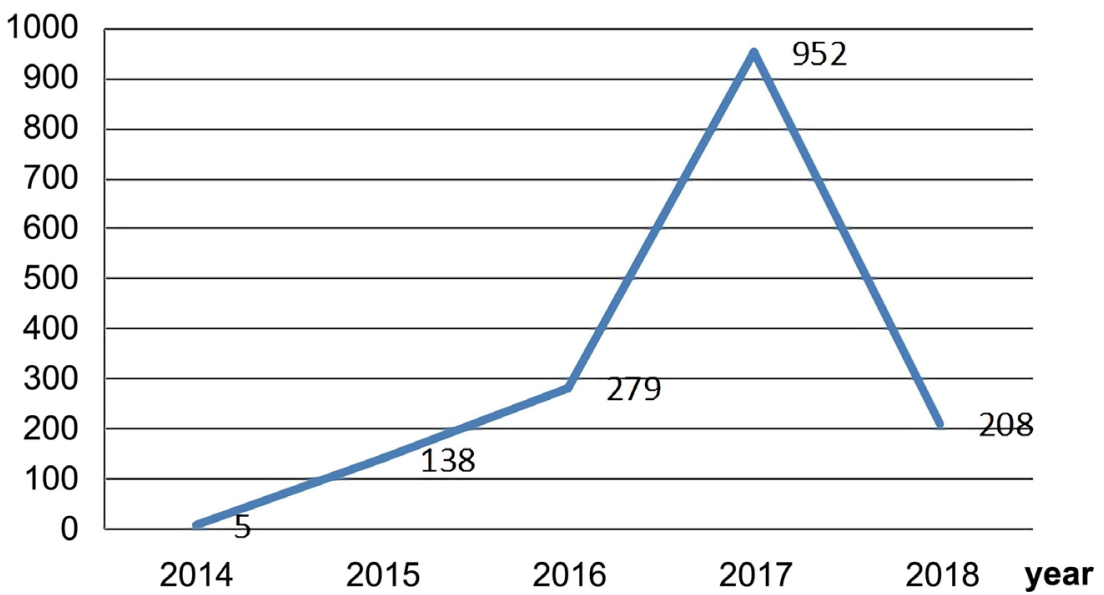

Figure 5. Trend map of creating characteristic towns in China.

\subsection{Dynamic Evolution of Small Towns with Chinese Characteristics Based on "Quantity-Spatial Distribution"}

According to the time dimension, the number and spatial distribution of Characteristic Towns in China are counted by polyline map and nuclear density map. It is found that the construction of characteristic towns in most provinces of China shows a trend of increasing to decreasing from 2015 to 2018 (Figure 6). Among them, 1) generally speaking, the provinces and the number of creating characteristic towns in 2015 are the least, while the provinces that created characteristic towns in 2017 are the most and the number of creating characteristic towns is the largest. 2016 is a transitional period, and the situation in the provinces is uneven. 2018 is the normative construction period of each province. 2) In terms of individual situation, the number of foundations in Guangdong, Sichuan, Liaoning and Guangxi provinces has been increasing gradually, while Hainan has been declining sharply after high-speed growth. Shandong, Yunnan, Hebei and Anhui have become major provinces in the construction of small towns with characteristics in 2017.

On the basis of Figure 6, the nuclear density of characteristic towns created in different years was analyzed, and the regional distribution trend of the construction of characteristic towns in China was obtained. 1) In 2015, the construction of small towns with national characteristics has just started, mainly distributed in Zhejiang and Hainan provinces. 2) In 2016, the construction and development of small towns with national characteristics was officially launched all over the country, mainly in the southeastern coastal areas of Jiangsu, Zhejiang and Fujian. 3) In 2017, the construction of small towns with national characteristics reached its peak, and small towns with special characteristics have spread all over the country. 4) In 2018, the intensive areas for the construction of characteristic towns were concentrated in Jiangsu, Zhejiang, Guangdong and Sichuan. Many provinces did not continue to build characteristic towns. In a word, during the period of 2015-2018, the construction layout of characteristic towns in China 


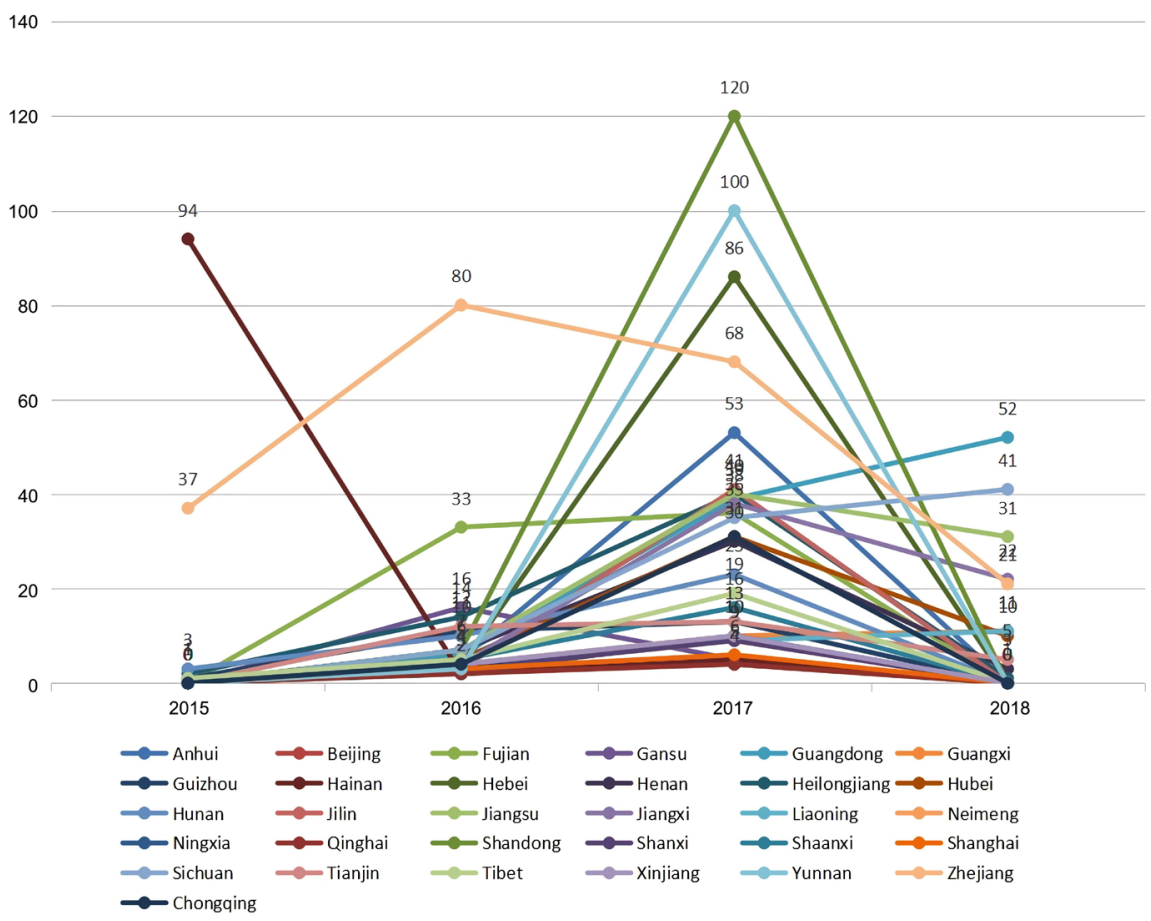

Figure 6. Trend map of characteristic towns in each province.

roughly formed the "Zhejiang-southeast coast—the whole country-southeast coast" transfer ladder. We believe that although the construction of characteristic towns throughout the country, with the passage of time, the drawbacks gradually emerge, the western region does not play a good role in the development of characteristic towns, while the eastern and southern regions of the characteristic towns develop faster, inevitably passed off fish eyes for pearls. The dynamic change of the construction layout of characteristic towns highlights the influence of policy, market, economy, industry and other factors on the construction of characteristic towns.

\subsection{Dynamic Evolution of Characteristic Towns Based on "Type-Spatial Distribution"}

Starting with the industrial types of characteristic towns, the spatial distribution trends of different types of characteristic towns are analyzed according to the time dimension, and the classification and development trend chart of the national characteristic towns is obtained (Figure 7). From Figure 7, we can see that the number of small towns with nine characteristics in China shows a trend of "less-more-less" with time. According to the annual growth rate of construction quantity: 1) manufacturing towns increased 225\% in 2016 compared with the same period in 2015 , the fastest growing category, followed by creative towns (150\%), tourism towns (105.1\%), information technology towns, business and logistics towns and cultural towns (all increased by 100\%), modern agricultural towns (68.2\%); medical health towns (11.1\%) and financial towns (negative growth);2) compared with 2016, the construction growth rate of all kinds of 


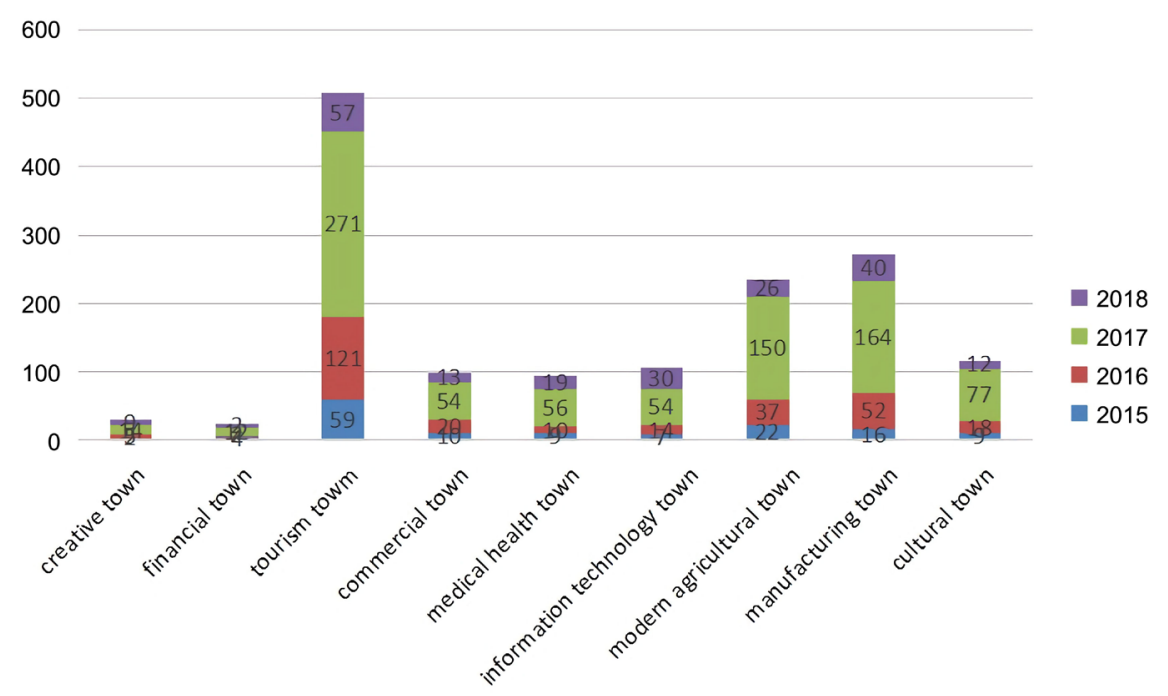

Figure 7. Development trend map of all kinds of characteristic towns in China.

small towns with special features has increased significantly, financial towns have increased by $500 \%$ year-on-year, followed by medical and health towns (460\%), cultural towns (327.8\%), modern agricultural towns (305.4\%), information technology towns (285.7\%), manufacturing towns (215.4\%), tourism towns (206.6\%), innovative and creative towns (180\%) and commercial towns (170\%). The above analysis results further reflect that: 1 ) in the initial stage of the establishment of characteristic towns in China, production and tourism were the main categories, while health and financial development were the slowest; 2) in the rapid development stage of characteristic towns, financial growth was the fastest, but the number was still small, medical and health, cultural and modern agriculture. Industry and information technology towns have received much attention, while tourism, creative towns and business and logistics towns, which were originally popular, have slowed down significantly. 3) By the standard development stage of 2018, information technology, manufacturing (high-end manufacturing), health care and innovative and creative towns will begin to occupy the main position and become the leading direction of development.

Next, starting from the spatial dimension, we use ArcGis software to visualize the spatial evolution of different types of towns in China. Because there are many types of towns, this paper does not present the visualization results one by one, and only shows the creative towns as an example (Figure 8). Finally, the following evolutionary rules are obtained. 1) Innovative and creative towns originated in Hainan, and only two were found. In 2016 and 2017, they gradually extended to Zhejiang, Jiangsu, Anhui, Fujian, Shandong and other Southeast Coastal areas, and developed to Guangdong after 2018. 2) Financial towns were first established in Zhejiang, and then developed to Beijing, Shandong, Shanghai, Guangdong and other areas with developed foreign trade. 3) There is no clear evolution law in the spatial distribution of cultural, tourism and modern agricultural towns. 4) Business and trade logistics towns were initially established in 


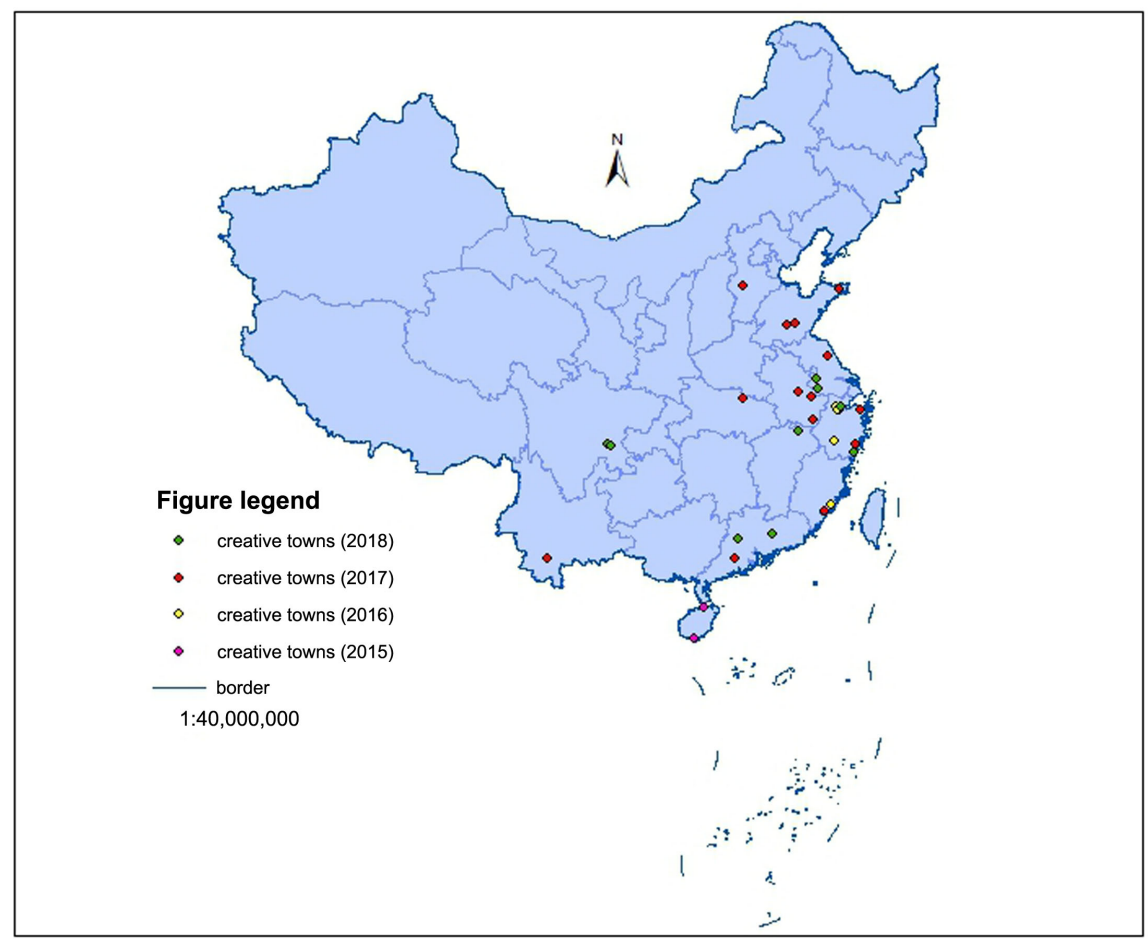

Figure 8. Spatial evolution path of creative town.

Hainan, Zhejiang, Beijing and other transportation hub areas. Later, with the development of China's logistics industry almost all over the country, they were mainly established in Guangdong after 2018. 5) Medical and health towns were initially mainly established in Hainan, Zhejiang, Beijing, Fujian and other places. These areas are either pleasant climate or good medical conditions. After 2017, they mainly concentrated in the Bohai Rim and the coastal areas of Guangdong Province. 6) The evolution trend of information technology towns is not obvious, which has been concentrated in Beijing, Jiangsu, Zhejiang, Guangdong and other areas where there are many talents, labor force and scientific research institutes. 7) Manufacturing towns form the distribution evolution law of "South-Bohai Rim-Jiangsu and Zhejiang".

\section{Main Conclusions and Policy Recommendations}

This paper uses big data method to analyze the static and dynamic evolution of the development of small towns with Chinese characteristics from two dimensions of space and type. The main conclusions are as follows.

1) The spatial distribution of characteristic towns is not balanced, showing the characteristics of intensive distribution. There is an obvious trend of agglomeration and hierarchy and decreasing from east to west. The Yangtze River Delta (especially Zhejiang) is the highest density heat zone in China; the Pearl River Delta is the highest density heat zone, while Liaoning, Heilongjiang, Shanxi and Shaanxi are the most dense heat zones. The characteristic towns in Gansu, Qinghai, Xinjiang and Tibet are scattered. 
2) Tourism towns, manufacturing towns and modern agricultural towns are developing fastest. There is still much room for the development of cultural, information technology, business logistics and health care towns, while innovative and creative towns and financial towns are developing relatively slowly. There are significant differences in spatial distribution density among different characteristic towns. The distribution of tourism towns and health towns is scattered. The agglomeration degree of manufacturing, culture, information technology, business logistics, innovative ideas and finance types of towns is relatively high, and the distribution of modern agricultural towns is relatively uniform.

3) Following the evolutionary track of "Enlightenment-Preliminary Development-High-speed Development-Normative Construction”, characteristic towns have formed a cascade transfer pattern of "Zhejiang-Southeast Coast-NationalSoutheast Coast”. In the early stage, tourism and manufacturing were the main types; in the rapid development stage, the growth rate of financial towns was the fastest, while medical and health, cultural, modern agriculture and information technology towns were paid attention to, but tourism, innovative and creative towns and commercial and logistics towns slowed down significantly; in the standardized development stage, information technology, manufacturing (high-end manufacturing), medical health towns and creative towns have become the dominant direction.

4) Generally speaking, the construction of characteristic towns in China is highly resource-rooted. Different types of towns are clustered in areas with better basic resources, but the quality of the development of small towns needs to be improved. The main manifestation is that tourism, modern agriculture and other towns depending on natural resources account for a higher proportion, while information science and technology account for a higher proportion. For example, tourism towns account for $38.83 \%$ of the country's characteristic towns, while financial towns account for only $1.26 \%$ of all characteristic towns.

5) It is gratifying to note that the development of characteristic towns is undergoing a transition from resource-driven to innovation-driven. In the early stage of development, the characteristic towns depending on natural resources such as tourism and eco-agriculture were the focus of construction. After the standardized development stage in 2018 , the towns driven by innovative resources such as science and technology, talents and finance, information technology, medical health, innovative ideas, high-end manufacturing and finance became the focus of construction. It shows that the characteristic towns of our country begin to develop to a higher level.

Based on the above analysis, in order to promote the healthy development of characteristic towns in China, we should focus on the following aspects to launch targeted support policies. Firstly, we should strengthen the construction of Characteristic Towns in the central and western regions and the Northeast regions. Secondly, we should attach importance to the transformation from characteristic towns to innovation-driven ones, and build characteristic towns into 
innovative spaces, platforms for industrial development and grasps of new urbanization by developing high-end industries and emerging industries. Thirdly, we should persist in guiding the healthy development of characteristic towns and prevent unfavorable situations such as excessive construction speed, overheated investment, lack of distinctive features and quick success and instant benefit.

\section{Conflicts of Interest}

The authors declare no conflicts of interest regarding the publication of this paper.

\section{References}

[1] Zhang, S.M. and Li, X.B. (2018) Spatial Distribution Characteristics and Regional Influencing Factors of Characteristic Towns in China. Resource Development \& Market, 8, 1074-1097.

[2] Xie, H., Li, Y.H. and Wei, Y.Y. (2018) Research on Spatial Structure Characteristics and Influencing Factors of Characteristic Towns in Zhejiang Province. Geographical Science, 8, 1283-1291.

[3] Fu, X.D. and Jiang, Y.W. (2017) Discussion on the Development Model of Characteristic Towns in China Based on the Rooted Perspective. China Soft Science, 8 102-111.

[4] Cheng, H.Y. (2018) Discussion on the Development Mechanism of Characteristic Small Towns-Theoretical and Practical Analysis Based on China's National Conditions. Academic Forum, 1, 122-127.

[5] Min, X.Q. (2017) Characteristic Town and Its Creation Path from the Perspective of Accurate Governance. Journal of Tongji University (Social Science Edition), 10, 54-60.

[6] Hu, M.Z. (2018) Cognitive Characteristics of Big Data Analysis. Studies in Dialectics of Nature, 1, 112-117.

[7] Mayer-Schönberger, V. and Cukier, K. (2013) Big Data: A Revolution That Will Transform How We Live, Work and Think. Houghton Mifflin Harcourt, Boston.

[8] Li, T. (2017) Research on Innovation System of Characteristic Towns in China from the Perspective of Industrial Agglomeration. Scientific Management Research, 6, 53-64.

[9] Wang, X.Z. (2016) "Characteristics" and "General" of Characteristic Town. Zhejiang Social Sciences, 3, 46-47. 